\title{
BMJ Open Educational disparities in hypertension, diabetes, obesity and smoking in Brazil: a trend analysis of 578977 adults from a national survey, 2007-2018
}

\author{
Pedro Toteff Dulgheroff, ${ }^{1}$ Luciana Saraiva da Silva, ${ }^{1}$ Ana Elisa Madalena Rinaldi, ${ }^{1}$ \\ Leandro F. M. Rezende, ${ }^{2}$ Emanuele Souza Marques, ${ }^{3}$ \\ Catarina Machado Azeredo (D) ${ }^{1}$
}

To cite: Dulgheroff PT, da Silva LS, Rinaldi AEM, et al. Educational disparities in hypertension, diabetes, obesity and smoking in Brazil: a trend analysis of 578977 adults from a national survey, 2007-2018. BMJ Open 2021;11:e046154. doi:10.1136/ bmjopen-2020-046154

- Prepublication history and additional online supplemental material for this paper are available online. To view these files, please visit the journal online (http://dx.doi.org/10. 1136/bmjopen-2020-046154).

Received 27 October 2020 Accepted 16 June 2021

Check for updates

(c) Author(s) (or their employer(s)) 2021. Re-use permitted under CC BY-NC. No commercial re-use. See rights and permissions. Published by BMJ.

${ }^{1}$ Faculdade de Medicina, Universidade Federal de Uberlandia, Uberlandia, MG, Brazil

${ }^{2}$ Universidade Federal de São Paulo, Escola Paulista de Medicina, Departamento de Medicina Preventiva, Sao Paulo, SP, Brazil

${ }^{3}$ Instituto de Medicina Social, Universidade do Estado do Rio de Janeiro, Rio de Janeiro, RJ, Brazil

Correspondence to Professor Catarina Machado Azeredo;

catarina.azeredo@ufu.br

\section{ABSTRACT}

Objectives Our study aimed to assess social inequality trends for hypertension, diabetes mellitus, smoking and obesity from 2007 to 2018 in adults from Brazilian capitals.

Setting Data from the Surveillance of Risk and Protection Factors for Chronic Diseases by Telephone Survey study, a cross-sectional telephone survey, conducted annually from 2007 to 2018.

Participants We used data from 578977 Brazilian adults ( $\geq 18$ years)

Design Cross-sectional surveys conducted annually from 2007 to 2018.

Primary outcome measures Participants responded to a questionnaire about medical diagnosis of hypertension and diabetes, smoking status, weight and height. Educational inequalities $(0-3,4-8,9-11$ and 12 or more years of study) by sex and skin colour were assessed trough absolute, Slope Index of Inequality (SII) and relative measures of inequality, Concentration Index and trends were tested by Prais-Winsten.

Results All outcomes were more prevalent in the least educated. The largest absolute educational inequality was observed for hypertension $\left(\mathrm{SII}_{\text {total }}=-37.8\right.$ in 2018). During 2007-2018, the total educational disparity remained constant for hypertension, increased for diabetes and smoking, and decreased for obesity. Overall, inequality was higher among women and non-whites, compared with men and whites. We found a reduction in absolute inequality for hypertension among non-whites, an increase for diabetes in all strata, and an increase for smoking in women and non-whites. The relative inequality decreased in women and whites and increased for smoking in all strata, except among men.

Conclusion The educational inequality reduced for obesity, remained constant for hypertension and increased for diabetes and smoking from 2007 to 2018 in Brazilian adults.

\section{INTRODUCTION}

Non-communicable diseases (NCD) are the main cause of death in Brazil ${ }^{1}$ and worldwide. $^{2}$ According to the Global Burden of Diseases, Injuries and Risk Factors Study, in
Strengths and limitations of this study

- We assessed the extent and trend of socioeconomic inequalities in major non-communicable diseases (hypertension and diabetes) and its risk factors (smoking and obesity) over 12 years in a middleincome country.

- We used large samples from Brazilian adults living in the 27 state Capitals in Brazil.

- We assessed educational inequalities in total sample and in subgroups of sex and race/skin colour using complex measures of inequality.

- Using data from a telephone Survey Surveillance of Risk and Protection Factors for Chronic Diseases by Telephone Survey limited our generalisability to those with landlines.

- The use of self-reported diseases may have affected our results underestimating inequality in hypertension and diabetes, as it may have underestimated the prevalence among least favoured groups.

2017, the four main risk factors for mortality and years of life lost due to disability in Brazil were systemic arterial hypertension, diabetes mellitus, obesity and smoking. ${ }^{3}$ Importantly, these risk factors affect the less economically favoured groups in a more pronounced way, ${ }^{4-6}$ in addition to reinforcing poverty and income inequality by generating an increase in direct and indirect spending and loss of productivity. ${ }^{7}$ A synthesis of 283 studies in lowincome and middle-income countries showed a positive association between low income, low socioeconomic status and low educational level with the occurrence of $\mathrm{NCD}{ }^{8}$ In Brazil, adults with less education, non-whites and without health insurance had a higher prevalence of risk factors for NCD, such as smoking, leisure time physical inactivity and lower consumption of fruits and vegetables. ${ }^{9}$

Trend analysis of the risk factors for NCD in Brazil showed that the prevalence of 
hypertension remained stable between 2006 and 2018, while diabetes and obesity grew and smoking dropped. ${ }^{10}$ However, this trend did not occur homogeneously among social strata. Between 1998 and 2013, there was a reduction in educational inequalities for hypertension and coronary heart disease and an increase in inequality for diabetes in Brazilian adults. ${ }^{5}$

A sustained reduction in health inequities between countries is necessary. ${ }^{8}$ However, trend studies on social inequality in the different risk factors for NCD that are essential for health planning are scarce in Brazil, ${ }^{5}$ especially assessing risk factors concomitantly and based on educational disparities, also considering sex and colour strata. Therefore, our aim was to assess social inequality trends for hypertension, diabetes, smoking and obesity among adults from Brazilian state capitals, from 2007 to 2018. We also performed subgroup analysis for education inequalities by skin colour and sex.

\section{METHODS}

\section{Study design and source of data and sample}

This study used data collected by the Surveillance of Risk and Protection Factors for Chronic Diseases by Telephone Survey (VIGITEL), coordinated by the Ministry of Health of Brazil, from 2007 to 2018. VIGITEL is a crosssectional system for monitoring the health of the adult population - over 18 years old, residing in the Brazilian capitals and the Federal District (DF), and who have a landline telephone-carried out annually since 2006. The sample stratification took place by telephone prefix until 2011, and subsequently by postal code (CEP). In order to reduce selection bias due to the partial coverage of the population by the landline telephone system, VIGITEL assigned a final weight to each individual, considering the inverse of the number of telephone lines in the household interviewed, the number of adults living in the household and the sociodemographic composition of the sample, based on the 2000 and 2010 demographic censuses. This weighting aimed to achieve representativeness for population aged 18 years and over of each state capital in Brazil, including DF in all years, ${ }^{10}$ but it cannot be used as a representative sample of the whole country. However, it had limitations previously described. ${ }^{11}$

Data from 625070 individuals interviewed between 2007 and 2018 were initially obtained. We excluded women who were pregnant and those who had doubts if they were or were not pregnant by the time of the interview (5087 women); people aged 80 or older (22234 individuals) because ageing may affect self-reports ${ }^{12}$; people who did not want to or did not know how to respond to their skin colour (20699 respondents), corresponding to a loss of $46093(7.4 \%)$ observations compared with the original study. Thus, 578977 participants were included in this study. During the analysis, there were two additional missing for skin colour and three missing for obesity.

All data of the participants were self-reported. They answered about previous medical diagnosis of hypertension and diabetes (all types), if they were current smokers (yes/no) and their weight and height, used to calculate the body mass index (BMI). We considered $\mathrm{BMI} \geq 30 \mathrm{~kg} / \mathrm{m}^{2}$ for obesity. ${ }^{13}$ Risk factors were described according educational level (ie, years of study number: $0-3,4-8,9-11$ and 12 or more study years), sex (women and men) and skin colour (white and non-white). Skin colour also was self-reported and included the categories: white (used for white colour) and black, brown, mixed race, yellow (Asian), red (ie, indigenous) and indigenous (used for non-white skin colour).

\section{Statistical analysis}

Prevalence of hypertension, diabetes, smoking and obesity (2007-2018) was age standardised using the age distribution of the year 2018. We estimated absolute and relative complex measures of inequality, namely the Slope Index of Inequality (SII) and the Concentration Index (CIX), respectively, and its $95 \%$ CI. These measures of inequality are complementary and were calculated according to $\mathrm{WHO}^{14}$ and Barros and Victora. ${ }^{15}$ The SII results from a linear regression of the cumulative population proportional distribution in each one of the four educational groups in this study and represents the absolute difference, in predicted values, on disease prevalence between the least and the most favoured person, with no education and the highest possible education, taking into consideration the entire distribution of the stratification variable. The CIX assesses the relative difference between them and shows how concentrated are the diseases towards the least or most favoured groups. CIX values should be read with caution because it can overestimate inequalities when the outcome of interest has a low frequency and may not be able to identify important inequalities when the outcome prevalence is high. ${ }^{16}$

The results of SII and CIX were multiplied by 100 to facilitate their visualisation in tables and graphs, ranging from -100 to +100 . On this scale, CIX values less than -20 or greater than 20 can be considered relevant indicators of inequality. ${ }^{14}$ Results equal to zero represent a situation of total equality. When it is equal +100 or -100 , we have the grater inequality possible. Negative values indicate a higher prevalence of the risk factor in the least educated group, while positive ones represents grater prevalence in those most educated groups.

The different levels of education were used to calculate the total SII and CIX. Subsequently, the SII and CIX data for educational level schooling were stratified by sex and skin colour. The time trend of the indicators was analysed using the Prais-Winsten method modified by Durbin and Watson instead of traditional linear regression to avoid the autoregressive problem common in this social serial trend analysis. ${ }^{17}$ Statistical analyses were performed using the STATA/SE V.15.1 software.

The VIGITEL database is in the public domain and does not allow identification of participants. It is available at the electronic address: http://svsaidsgovbr/download/ Vigitel/. 


\section{Patient and public involvement}

No patients or public were involved in the design, or conduct or reporting, or dissemination plans of our research.

\section{RESULTS}

From 2007 to 2018, the profile of individuals evaluated remained similar, with a slight increase $(\mathrm{p}=0.001)$ in the average of age (from 39.8 to 41.7 years) and similar distribution between sexes $(\mathrm{p}=0.858 \%-53.2 \%$ female $)$ and skin colour ( $\mathrm{p}=0.154 \%-58.6 \%$ non-white) in 2018. The average number of years of study showed a significant increase in the period, from 9.4 to 10.7 years of study $(\mathrm{p}=0.001)$. The prevalence of hypertension remained constant in the period $(34.1 \%$ in 2007 to $33.3 \%$ in 2018 $-\mathrm{p}=0.065$ ), with a reduction in smoking (from $13.0 \%$ to $7.4 \%-\mathrm{p}=0.001)$, while the prevalence of diabetes $(8.9 \%$ to $10.6 \%-\mathrm{p}=0.004)$ and obesity increased $(14.7 \%$ to $20.0 \%-\mathrm{p}=0.001$ ) (table 1). Descriptive data stratified by sex and skin colour can be found in online supplemental table 1 .

An educational gradient was observed for all four outcomes, with a higher prevalence among the least educated group. The largest relative prevalence discrepancy in 2018, between the least and the most educated groups, was observed for diabetes (24.4\% and 6.4\%) resulting in a difference of 18.0 percentage points and the smallest for smoking $(9.0 \%$ and $5.6 \%)$, where the prevalence difference between groups was 3.4 percentage points. Detailed data can be found in figure 1 and online supplemental tables $2-5$. For hypertension and obesity, these prevalence differences were: $60.7 \%$ vs $23.8 \%$ and $28.4 \%$ vs $16.8 \%$, respectively.

Hypertension, diabetes and obesity were more prevalent in women than in men, while smoking prevalence was higher in men. The prevalence of outcomes was higher in non-whites compared with whites for hypertension and obesity, and lower for diabetes and smoking. Online supplemental figures 1 and 2 and online supplemental tables 2-5 show the age-standardised prevalence of each outcome by years of study and stratified by sex, skin colour and education.

Table 2 shows the absolute (SII) and relative (CIX) measures of educational inequality for the four outcomes and also by sex and skin colour. Negative SII and CIX values for all outcomes reaffirm their higher prevalence among least educated group.

The absolute and relative educational inequality for hypertension, diabetes and obesity was, in general, higher among women than men and higher in non-white individuals compared with whites, represented by negative and higher SII and CIX values (figures 2-4). The exception was smoking, where SII and CIX were higher in men. Obesity showed higher absolute and relative inequality among whites (figure 4). Over the period, absolute and relative inequality remained constant in hypertension (figure 2; $\mathrm{p}=0.701$ and 0.658 , respectively), being higher in women than in men (figure 3) and in non-whites in relation to whites (figure 4). The absolute inequality in diabetes had a statistically significant increase in all strata (figures 2-4; $\mathrm{p}<0.05$ ). This increase was greater in men than in women, as well as in whites in relation to non-whites. The relative inequality in diabetes remained constant over the period $(\mathrm{p}=0.350)$. The absolute inequality for obesity remained constant $(\mathrm{p}=0.251)$, although there was a reduction in the relative inequality for the total sample and between women and non-whites (figures 2-4; $\mathrm{p}=0.010,0.009$ and 0.011 , respectively). There was an increase in absolute inequality in smoking between whites $(p=0.004)$ and women $(p=0.025)$ during the analysed period. The relative inequality in smoking increased in all strata $(\mathrm{p}<0.05)$, except among men, where it remained constant (figures 2-4).

\section{DISCUSSION}

In our study, diabetes, hypertension, obesity and smoking remained more prevalent in the least educated groups from 2007 to 2018 in Brazil. The absolute and relative educational inequalities were higher among women and non-whites, compared with men and whites. Hypertension was the outcome that had the highest absolute educational inequality, which remained constant in the period; the absolute educational inequality for diabetes increased in all strata. The absolute educational inequality remained constant for obesity, although the relative one has reduced for the total sample, among women and nonwhites. There was an increase in the absolute educational inequality for smoking among women and whites and relative educational inequality for all strata, except for men where it remained constant.

Hypertension had higher prevalence $(33.3 \%$ in 2018$)$ and the highest absolute educational inequality $(-37.8$ in 2018). The prevalence in the least educated group was $60.7 \%$. A study carried out with Brazilian adults found that ageing, black skin colour, low education, obesity, being a former smoker, self-reported diabetes, high cholesterol and high salt intake were associated with a higher prevalence of hypertension. ${ }^{18}$ In addition to individual factors, a study conducted with the North American population indicated that states with greater socioeconomic vulnerability, such as low family income and high percentages of the population below the poverty line were significantly associated with a high prevalence of self-reported hypertension, ${ }^{19}$ which corroborates with the inequality findings in our study. However, although we found the highest educational inequality for hypertension, it remained constant in the period. On the other hand, educational inequality for diabetes increased in this period in all strata. Diabetes had the highest relative inequity in $2018(-24.0)$. Trend analysis of the prevalence of diabetes, hypertension and heart disease from 1998 to 2013 also found an increase in diabetes disparities among a representative sample of Brazilian adults. ${ }^{5}$ It is possible that strategies such as the Brazilian National 


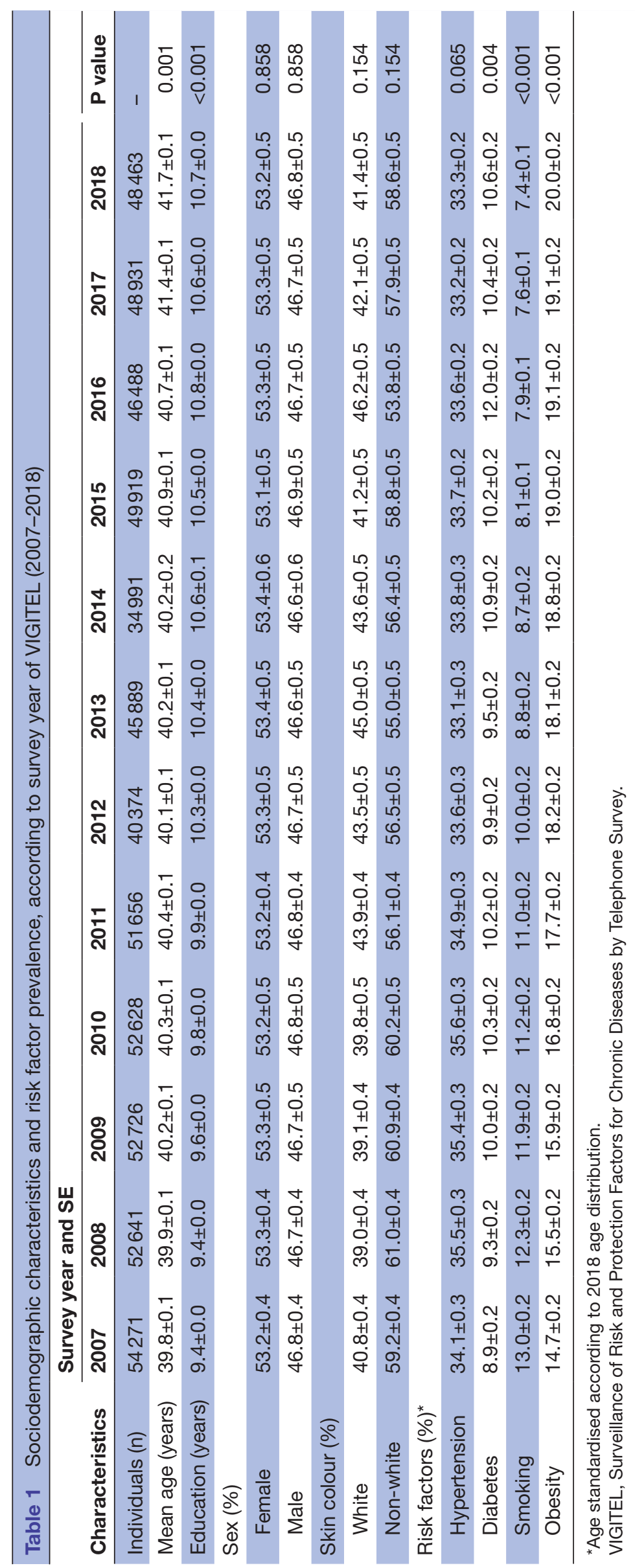



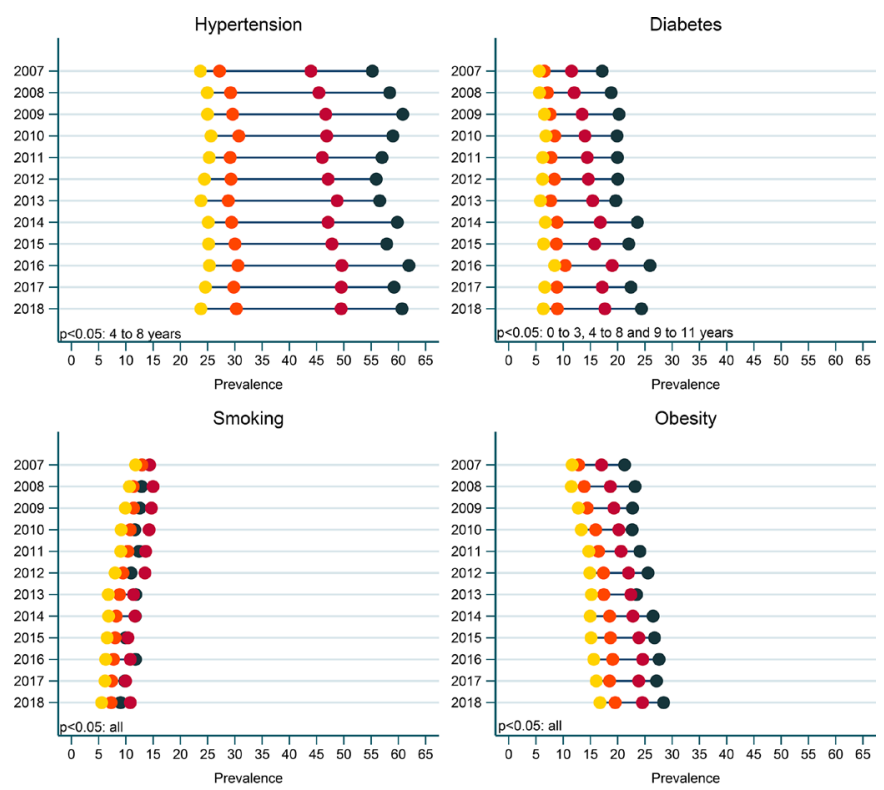

Years of education

- 0 to 3 vers 4 to 8 vers 9 to 11 vers 12 ormorevera

Figure 1 Age-standardised prevalence of hypertension, diabetes, smoking and obesity by years of education and survey year from 2007 to 2018. VIGITEL, 2007-2018. VIGITEL, Surveillance of Risk and Protection Factors for Chronic Diseases by Telephone Survey.

Policy for the Comprehensive Health of the Black Population, ${ }^{20}$ could have contributed to reduce race inequality by decreasing the prevalence of hypertension among non-whites. However, if this is true, we would expect to find a reduction in race inequality for diabetes. There are several potential explanations for the increase in educational inequalities for diabetes. This could have been partially driven by our finding of an increase in obesity prevalence over time, and higher prevalence among those less educated. Obesity is a stronger risk factor for diabetes than for hypertension. ${ }^{21} 22$ It is also possible that the increase in primary care coverage has provided access to healthcare and, consequently, increased the diagnosis of diabetes among those underprivileged (ie, therefore, artificially increasing the diabetes inequality). The National Programme for Improving Access and Quality in Primary Care and the Requalification Programme for Basic Health Units (Programa Nacional de Melhoria do Acesso e da Qualidade da Atenção Básica), created in 2011, as well as the More Doctors for Brazil Project (Mais Médicos para o Brasil), created in 2013, increased the number of health units and physicians' access to more than 65 million people. ${ }^{23}$ If that was the case, we would expect increase in social inequality for hypertension too. ${ }^{24}$ Unless the requirement of fewer medical supplies for hypertension diagnosis compared with diabetes ${ }^{24}$ causes less underreport for hypertension and, therefore, benefits less from the extension in primary care coverage not affecting the inequality.

The increase in obesity prevalence over time, especially among the least educated group, have been reported in other countries. $^{25}$ This can be explained by the lower

Table 2 Age-standardised Slope Index of Inequality (SII) and Concentration Index (CIX) in hypertension, diabetes, smoking and obesity

\begin{tabular}{|c|c|c|c|c|c|c|}
\hline \multirow[b]{2}{*}{ Risck factor } & \multicolumn{3}{|l|}{ SII (95\% Cl) } & \multicolumn{3}{|l|}{ CIX (95\% Cl) } \\
\hline & 2007 & 2018 & $P$ value & 2007 & 2018 & $P$ value \\
\hline Hypertension & $-36.8(-38.8$ to -34.9$)$ & $-37.8(-39.3$ to -36.2$)$ & 0.701 & $-15.9(-16.9$ to -14.9$)$ & $-16.0(-16.8$ to -15.2$)$ & 0.658 \\
\hline Male & $-20.2(-23.3$ to -17.0$)$ & $-23.5(-26.0$ to -21.0$)$ & 0.641 & $-9.2(-11.0$ to -7.5$)$ & $-9.9(-11.4$ to -8.4$)$ & 0.916 \\
\hline White & $-33.5(-36.6$ to -30.4$)$ & $-35.5(-37.8$ to -33.2$)$ & 0.757 & $-14.3(-15.9$ to -12.7$)$ & $-14.3(-15.6$ to -13.0$)$ & 0.317 \\
\hline Female & $-15.9(-17.9$ to -13.9$)$ & $-19.9(-21.5$ to -18.4$)$ & 0.001 & $-24.6(-27.5$ to -21.7$)$ & $-26.9(-29.0$ to -24.8$)$ & 0.708 \\
\hline Male & $-6.8(-8.9$ to -4.6$)$ & $-13.4(-15.3$ to -11.6$)$ & 0.001 & $-10.8(-15.0$ to -6.7$)$ & $-17.7(-20.6$ to -14.9$)$ & 0.056 \\
\hline White & $-11.1(-13.4$ to -8.9$)$ & $-15.7(-17.5$ to -14.0$)$ & 0.001 & $-19.0(-22.8$ to -15.1$)$ & $-21.1(-23.7$ to -18.4$)$ & 0.616 \\
\hline Non-white & $-14.0(-16.1$ to -12.0$)$ & $-19.7(-21.3$ to -18.1$)$ & 0.001 & $-21.2(-24.3$ to -18.1$)$ & $-26.4(-28.6$ to -24.2$)$ & 0.128 \\
\hline White & $-0.4(-2.6$ to 1.7$)$ & $-4.3(-5.8$ to -2.8$)$ & 0.004 & $-1.0(-3.7$ to 1.7$)$ & $-6.6(-9.7$ to -3.5$)$ & 0.001 \\
\hline Non-white & $-4.4(-6.2$ to -2.6$)$ & $-8.7(-10.0$ to -7.4$)$ & 0.433 & $-5.4(-7.6$ to -3.2$)$ & $-18.2(-20.9$ to -15.4$)$ & 0.008 \\
\hline Obesity & $-10.8(-12.4$ to -9.2$)$ & $-12.2(-13.6$ to -10.7$)$ & 0.251 & $-11.3(-13.0$ to -9.6$)$ & $-8.6(-9.8$ to -7.4$)$ & 0.010 \\
\hline Female & $-16.6(-18.7$ to -14.5$)$ & $-18.0(-19.8$ to -16.2$)$ & 0.701 & $-17.4(-19.5$ to -15.2$)$ & $-12.9(-14.4$ to -11.5$)$ & 0.009 \\
\hline Male & $-0.4(-2.7$ to 1.9$)$ & $-0.8(-3.1$ to 1.5$)$ & 0.137 & $-0.5(-3.0$ to 2.0$)$ & $-0.2(-2.0$ to 1.7$)$ & 0.307 \\
\hline White & $-9.7(-12.1$ to -7.3$)$ & $-11.9(-14.0$ to -9.8$)$ & 0.075 & $-11.0(-13.7$ to -8.2$)$ & $-8.4(-10.3$ to -6.6$)$ & 0.145 \\
\hline Non-white & $-11.2(-13.3$ to -9.1$)$ & $-11.9(-13.8$ to -10.0$)$ & 0.822 & $-10.9(-13.0$ to -8.8$)$ & $-8.1(-9.6$ to -6.6$)$ & 0.011 \\
\hline
\end{tabular}




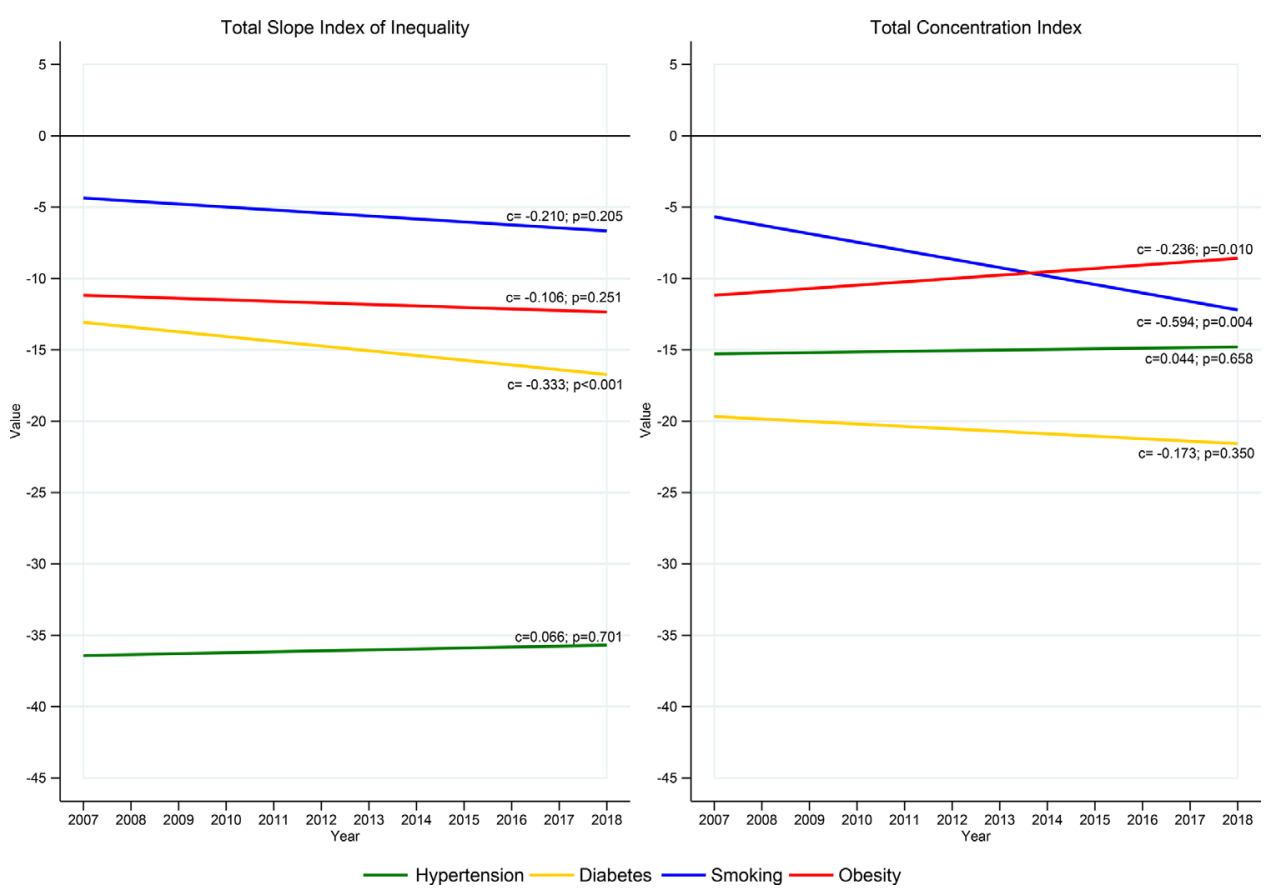

Figure 2 Trends in total Slope Index of Inequality and Concentration Index for age-standardised prevalence of hypertension, diabetes, smoking and obesity, VIGITEL 2007-2018. C, annual change of index; p, p value. VIGITEL, Surveillance of Risk and Protection Factors for Chronic Diseases by Telephone Survey.

financial access to healthy food in addition to fewer opportunities to engage in leisure physical activities. ${ }^{26}$ The gap in obesity prevalence between least and the most educated groups reduced over time, but it was not sufficient to impact SII indicator. However, due to an increase in obesity prevalence in all education groups, especially in those with 9-11 study years $(53,1 \%$ while prevalence raised $33,3 \%$ in people with less than 4 years of study), relative inequality reduced. This reduction in relative inequality is an artificial change that should not be read as an achievement because does not reflect a beneficial change in inequality, but rather a worsening scenario for all strata of education. Brazil still lacks strong initiatives to protect the more vulnerable groups and tackle the social inequalities for obesity such as regulation of nutritional labelling claims and health warnings, advertising
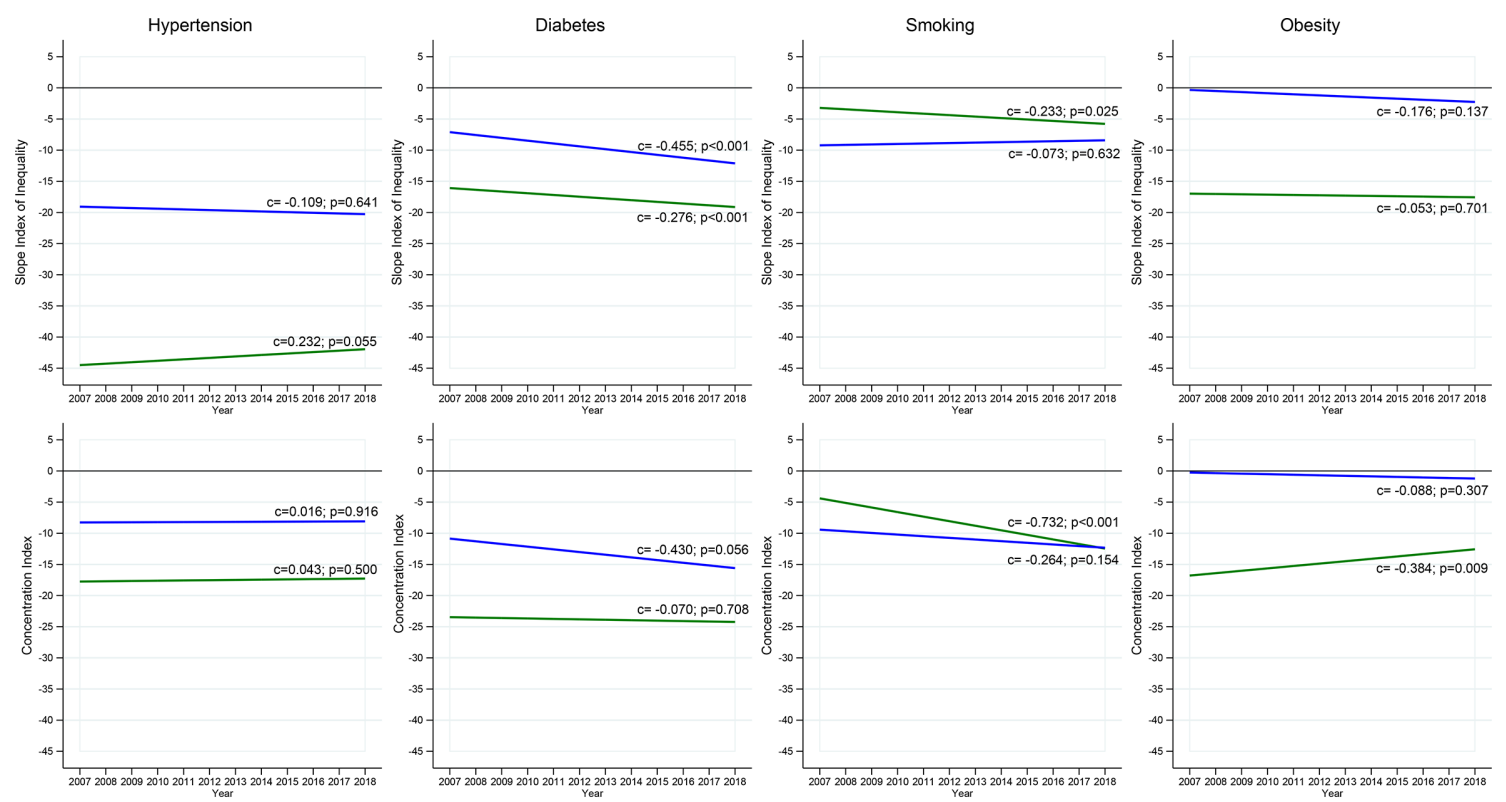

- Female-Male

Figure 3 Trends in Slope Index of Inequality and Concentration Index for age-standardised prevalence of hypertension, diabetes, smoking and obesity by sex, VIGITEL 2007-2018. C, annual change of index; p, p value. VIGITEL, Surveillance of Risk and Protection Factors for Chronic Diseases by Telephone Survey. 

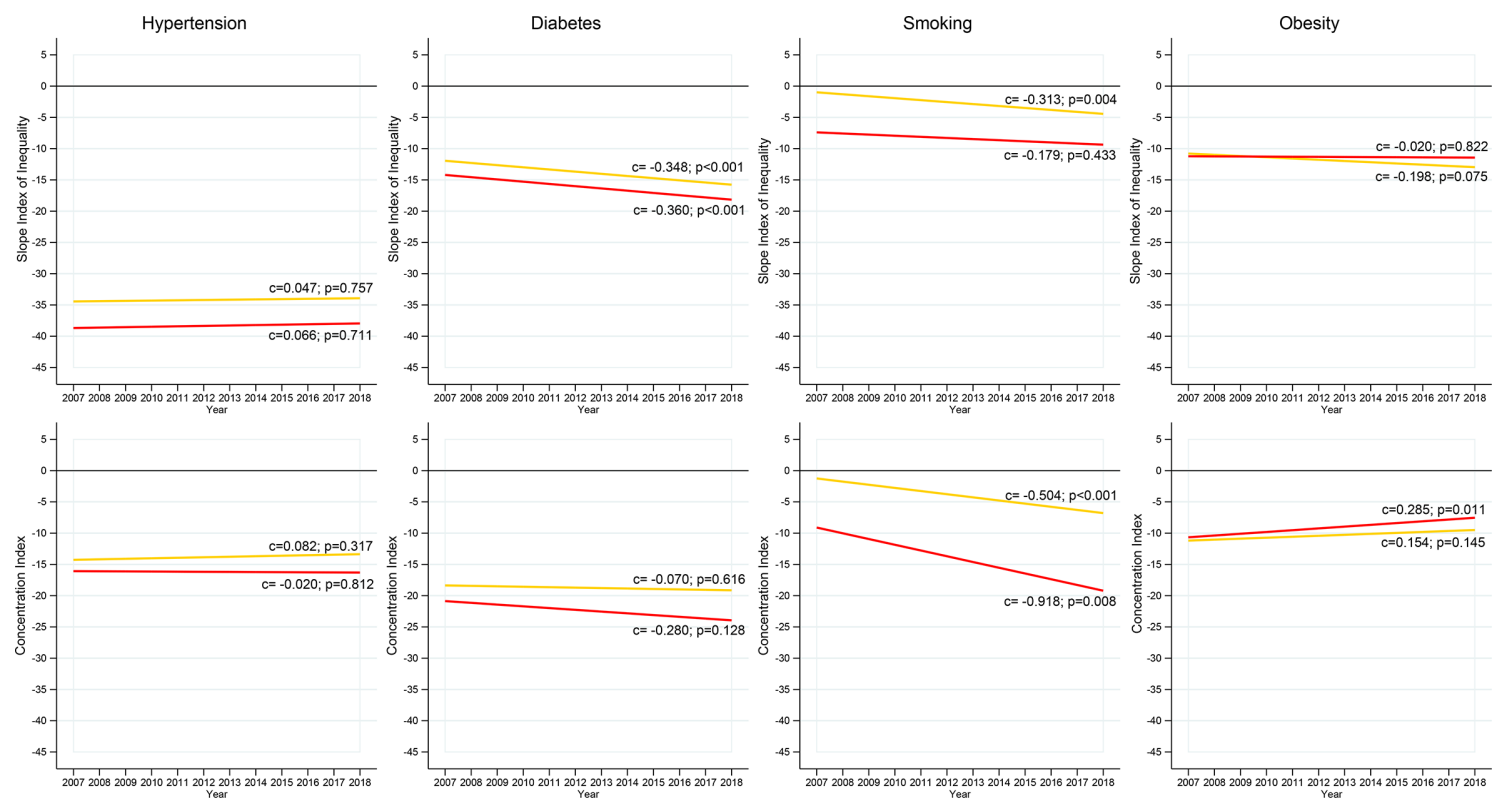

White - Non-White
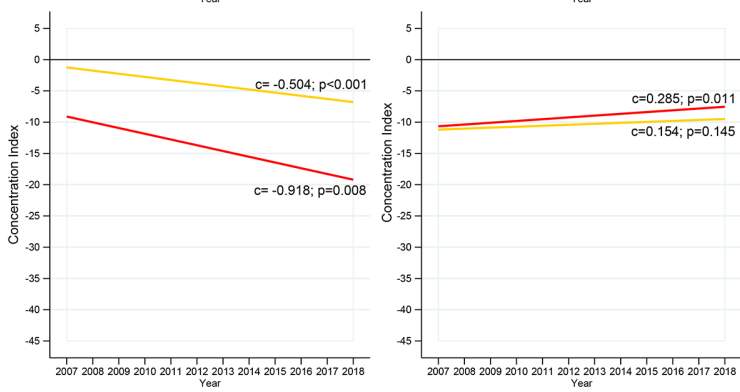

Non-White

Figure 4 Trends in Slope index of Inequality and Concentration Index for age-standardised prevalence of hypertension, diabetes, smoking and obesity by skin colour, VIGITEL 2007-2018. C, annual change of index; p, p value. VIGITEL, Surveillance of Risk and Protection Factors for Chronic Diseases by Telephone Survey.

restrictions, protection of the food school environment and taxation of unhealthy food, ${ }^{27}$ jointly with a broad promotion of active commuting and availability of public spaces for physical activity. ${ }^{28}$

Our results confirm the global decrease trend in smoking prevalence, ${ }^{29}$ with a sharper reduction among the most educated adults. ${ }^{30}$ This explained the increase in the relative educational inequality in most strata, except among men. Several actions have been taken to halt smoking, such as the ratification of the WHO Framework Convention on Tobacco Control in 2005, which resulted in the Brazilian National Tobacco Control Policy. ${ }^{31}$ These policies may have had less impact the least educated people ${ }^{32}$ increasing social inequality. Although actions, such as the taxation of tobacco products, immediately affect low-income individuals, over time they resort to the illegal market, maintaining the cigarette use. Recent work shows that, in Brazil, the illegal cigarette market grew from $28.6 \%$ in 2012 to $42.8 \%$ in $2016 .{ }^{33}$ Moreover, most actions aimed at changing behaviour in favour of smoking cessation are educational, requiring cognitive skills for better understanding and, thus, more educated people will benefit more from these interventions. ${ }^{34}$ In addition, tobacco companies have intensified marketing strategies to reach vulnerable populations, such as women, ${ }^{35}$ which may also justify the higher inequality in this group.

Educational inequality has disproportionately affected women and non-whites in Brazil. Although women have had more schooling than men in Brazil, their average income has been lower. ${ }^{36}$ Illiteracy among women aged 15 years and over non-white was more than double that of white women $(10.2 \%$ and $4.9 \%$, respectively). Although there was an improvement in the education of the non-white adult population with 12 or more years of study between 1995 and 2015 (from 3.3\% to 12\%), this percentage among whites was more than twofold higher in 2015 (25.9\%). ${ }^{36}$ In Brazil, unlike other countries, social inequality drives racial disparities. ${ }^{37}$ Black people have less access to healthcare, less quality of healthcare and are less informed about health promotion and disease prevention. ${ }^{38}$

We found punctual reduction in the disparities for obesity, and an increase in disparities for diabetes and smoking, that are all modifiable risk factors sensitive to strategies promoting health lifestyle. ${ }^{39}$ Accordingly, policies targeting the vulnerable groups, such as income redistribution, ${ }^{40}$ a strong and broad social security system and health education and promotion, would avoid the reinforcement of the current inequalities ${ }^{8}$ and bring better health outcomes for Brazilians. In the last decades, Brazil has adopted several policies that could mitigate socioeconomic inequalities, with the potential to alter the prevalence of risk factors for NCDs, such as the expansion of primary healthcare, through the Family Health Strategy, and conditional cash transfer, through Bolsa Família Programme. These policies increased the access of the low-income population to health promotion and disease prevention actions. ${ }^{4142}$ Launched in 2011 by the Minister of Health of Brazil, the Strategic Action Plan for Tackling Chronic NCD in Brazil has made advances in surveillance (eg, national surveys and monitoring of mortality and risk factor reduction targets); health promotion (eg, encouragement of physical activity, adequate nutrition and health promotion through the creation of the Health Gym Programme); regulation (eg, legislation on tobacco-free environments); and healthcare (eg, free 
of charge drugs for hypertension, diabetes and asthma; organisation of the emergency service network for cardiovascular diseases).$^{43}$ More recently, a new plan for Tackling NCD in Brazil from 2021 to 2030 has been launched by the Minister of Health of Brazil, and it is guided to prevent NCD, promote health, while reducing health inequalities. ${ }^{44}$ Despite efforts, limited advances have been achieved. Health inequality is a persistent phenomenon. ${ }^{45}$ Moreover, since 2014, Brazil has been facing an economic crisis and recently adopted austerity policies that could negatively impact health inequality trends. ${ }^{46}$

Our results may serve as a starting point for new studies that can deepen into the causes that led to the reductions in educational inequalities observed for hypertension and obesity. Future studies also need to understand the reasons for an increase in educational inequality for diabetes and smoking.

Our study has some limitations. VIGITEL survey collected data only from the population with landlines and included only the adults living in Brazilian capitals and the DF. Despite using weighting measures for the general population, we would expect some small differences in the prevalence of our outcomes if we had assessed a sample that was not limited by landline access. ${ }^{11}$ Over time, the access to landlines has reduced, and older and wealthier households are more likely to have and retain a landline in addition to a mobile phone. Therefore, the set of those contacted in a landline-only survey will increasingly skew towards those older/ wealthier groups. This may have underestimated the prevalence of NCD in those places with less landlines access. ${ }^{47}$ Future studies need to assess social inequality for NCD in rural areas. ${ }^{8}$ In addition, risk factors were self-reported and may be underestimated, especially medical diagnosis of diabetes and hypertension. This may have affected our results underestimating inequality in hypertension and diabetes, as it may have underestimated the prevalence among the least favoured groups.

In conclusion, we observed maintenance in the educational gap for hypertension and decreased relative inequity in general obesity and among female and non-whites. The reduction in inequality for obesity should be read with caution because it reflects increases in obesity prevalence in all groups. The absolute educational inequality increased for diabetes in all strata and increased in absolute and relative forms for smoking in almost all strata.

Contributors PTD contributed to data analysis and interpretation and to drafting and revising the manuscript and figures. CMA, LSdS, AEMR, LFMdR and ESM contributed to study concept and design, data interpretation, revising the manuscript and figures, and final approval of the version submitted.

Funding This research received financial support from the Brazilian National Council of Scientific and Technological Development (CNPq), 404905/2016-1, awarded to CMA.

Disclaimer The study sponsor was not involved in the study's design; the collection, analysis, and interpretation of data; writing the report; or the decision to submit the report for publication.

Competing interests None declared.

Patient consent for publication Not required.
Ethics approval VIGITEL was approved by the National Research Ethics Commission (CONEP). The waiver of ethical review was approved by the Research Ethics Committee of the Federal University of Uberlândia, Minas Gerais (CAAE: 2 654 271).

Provenance and peer review Not commissioned; externally peer reviewed.

Data availability statement Data are available in a public, open access repository. All datasets of VIGITEL are publicly available at: http://svs.aids.gov.br/download/ Vigitel/

Supplemental material This content has been supplied by the author(s). It has not been vetted by BMJ Publishing Group Limited (BMJ) and may not have been peer-reviewed. Any opinions or recommendations discussed are solely those of the author(s) and are not endorsed by BMJ. BMJ disclaims all liability and responsibility arising from any reliance placed on the content. Where the content includes any translated material, BMJ does not warrant the accuracy and reliability of the translations (including but not limited to local regulations, clinical guidelines, terminology, drug names and drug dosages), and is not responsible for any error and/or omissions arising from translation and adaptation or otherwise.

Open access This is an open access article distributed in accordance with the Creative Commons Attribution Non Commercial (CC BY-NC 4.0) license, which permits others to distribute, remix, adapt, build upon this work non-commercially, and license their derivative works on different terms, provided the original work is properly cited, appropriate credit is given, any changes made indicated, and the use is non-commercial. See: http://creativecommons.org/licenses/by-nc/4.0/.

ORCID iD

Catarina Machado Azeredo http://orcid.org/0000-0002-6189-4429

\section{REFERENCES}

1 Malta DC, Andrade SSCdeA, Oliveira TP, et al. Probability of premature death for chronic non-communicable diseases, Brazil and regions, projections to 2025. Rev Bras Epidemiol 2019;22:e190030.

2 GBD 2016 Causes of Death Collaborators. Global, regional, and national age-sex specific mortality for 264 causes of death, 19802016: a systematic analysis for the global burden of disease study 2016. Lancet 2017;390:1151-210.

3 GBD 2017 Risk Factor Collaborators. Global, regional, and national comparative risk assessment of 84 behavioural, environmental and occupational, and metabolic risks or clusters of risks for 195 countries and territories, 1990-2017: a systematic analysis for the global burden of disease study 2017. Lancet 2018;392:1923-94.

4 Zhao D, Post WS, Blasco-Colmenares E, et al. Racial differences in sudden cardiac death. Circulation 2019;139:1688-97.

5 Beltrán-Sánchez H, Andrade FCD. Time trends in adult chronic disease inequalities by education in Brazil: 1998-2013. Int J Equity Health 2016:15:139.

6 Strong K, Mathers C, Leeder S, et al. Preventing chronic diseases: how many lives can we save? Lancet 2005;366:1578-82.

7 Nugent R, Bertram MY, Jan S, et al. Investing in non-communicable disease prevention and management to advance the sustainable development goals. Lancet 2018;391:2029-35.

8 Niessen LW, Mohan D, Akuoku JK, et al. Tackling socioeconomic inequalities and non-communicable diseases in low-income and middle-income countries under the sustainable development agenda. Lancet 2018;391:2036-46.

9 de Azevedo Barros MB, Lima MG, Medina LdePB, et al. Social inequalities in health behaviors among Brazilian adults: National health survey, 2013. Int J Equity Health 2016;15:148.

10 Ministério da saúde. Vigilância de fatores de risco e proteção para doençascrônicas por inquérito telefônico. In: Vigitel brasil. , 2018: 2019, 132.

11 Bernal RTI, Malta DC, Claro RM, et al. Effect of the inclusion of mobile phone interviews to Vigitel. Rev Saude Publica 2017;51:15s

12 Knäuper $\mathrm{B}$, Carrière $\mathrm{K}$, Chamandy $\mathrm{M}$, et al. How aging affects selfreports. Eur J Ageing 2016;13:185-93.

13 WHO. Obesity: preventing and managing the global epidemic Report of a who consultation. World Health Organ Tech Rep Ser 2000;894:1-253.

14 WHO. Handbook on health inequality monitoring: with a special focus on low- and middle-income countries. Geneva: WHO press, 2013: 105.

15 Barros AJD, Victora CG. Measuring coverage in $\mathrm{MNCH}$ : determining and interpreting inequalities in coverage of maternal, newborn, and child health interventions. PLoS Med 2013;10:e1001390. 
16 Silva ICMda, Restrepo-Mendez MC, Costa JC, et al. Measurement of social inequalities in health: concepts and methodological approaches in the Brazilian context. Epidemiol Serv Saude 2018;27:e000100017.

17 Antunes JLF, Cardoso MRA. Uso dA análise de séries temporais em estudos epidemiológicos. Epidemiologia e Serviços de Saúde 2015;24:565-76.

18 Malta DC, Bernal RTI, Andrade SSCdeA, et al. Prevalence of and factors associated with self-reported high blood pressure in Brazilian adults. Rev Saude Publica 2017;51:11s.

19 Fan AZ, Strasser SM, Zhang X, et al. State socioeconomic indicators and self-reported hypertension among US adults, 2011 behavioral risk factor surveillance system. Prev Chronic Dis 2015;12:E27

20 Ministério da saúde. Política nacional de saúde integral dapopulação negrauma política do sus. 3 edn. Brasília - DF, 2017.

21 Guh DP, Zhang W, Bansback N, et al. The incidence of comorbidities related to obesity and overweight: a systematic review and meta-analysis. BMC Public Health 2009;9:88.

22 Lanas F, Seron P. Diverging trends in obesity, diabetes, and raised blood pressure in the Americas. Lancet Glob Health 2020;8:e18-19.

23 Facchini LA, Tomasi E, Dilélio AS. Qualidade dA Atenção Primária à Saúde no Brasil: avanços, desafios E perspectivas. Saúde em Debate 2018;42:208-23.

24 Ministério da saúde. Estratégias para O cuidado dapessoacom doença crônica. Brasil, 2014: 162.

25 Hulsegge G, Picavet HSJ, Blokstra A, et al. Today's adult generations are less healthy than their predecessors: generation shifts in metabolic risk factors: the Doetinchem cohort study. Eur J Prev Cardiol 2014;21:1134-44.

26 Malta DC, Santos MAS, Andrade SSCdeA, et al. Tendência temporal DOS indicadores de excesso de peso em adultos nas capitais brasileiras, 2006-2013. Ciênc. saúde coletiva 2016;21:1061-9.

27 Huang TT-K, Cawley JH, Ashe M, et al. Mobilisation of public support for policy actions to prevent obesity. Lancet 2015;385:2422-31.

28 Malta DC, Barbosa da Silva J. Policies to promote physical activity in Brazil. Lancet 2012;380:195-6.

29 Bruthans J, Mayer O, De Bacquer D, et al. Educational level and risk profile and risk control in patients with coronary heart disease. Eur $J$ Prev Cardiol 2016;23:881-90.

30 Eliasson M, Eriksson M, Lundqvist R, et al. Comparison of trends in cardiovascular risk factors between two regions with and without a community and primary care prevention programme. Eur J Prev Cardiol 2018;25:1765-72.

31 Cavalcante TM, Pinho MCMde, Perez CdeA, et al. Brasil: balanço dA Política Nacional de Controle do Tabaco Na última década $\mathrm{E}$ dilemas. Cadernos de Saúde Pública 2017;33.
32 Bazotti A, Finokiet M, Conti IL, et al. Tabagismo E pobreza no Brasil: uma análise do perfil dA população tabagista a partir dA POF 20082009. Ciênc. saúde coletiva 2016;21:45-52.

33 Szklo A, Iglesias RM, Carvalho de Souza M, et al. Trends in illicit cigarette use in Brazil estimated from legal sales, 2012-2016. Am J Public Health 2018;108:265-9.

34 STd S, Martins MC, FRd F, et al. Combate AO Tabagismo no Brasil: a importância estratégica das ações governamentais. Ciência \& Saúde Coletiva 2014;19:539-52.

35 Doku D. The tobacco industry tactics-a challenge for tobacco control in low and middle income countries. Afr Health Sci 2010;10:201-3.

36 IPEA. Retrato das Desigualdades de Gênero e Raça-1995 a 2015 4ed. Brasilia: IPEA, 2011

37 Victora C. Socioeconomic inequalities in health: reflections on the academic production from Brazil. Int J Equity Health 2016;15:164.

38 IFMSA. IFMSA policy document ethnicity and health. Montreal, Canada, 2018.

39 Piepoli MF, Hoes AW, Agewall S, et al. 2016 European Guidelines on cardiovascular disease prevention in clinical practice: The Sixth Joint Task Force of the European Society of Cardiology and Other Societies on Cardiovascular Disease Prevention in Clinical Practice (constituted by representatives of 10 societies and by invited experts) Developed with the special contribution of the European Association for Cardiovascular Prevention \& Rehabilitation (EACPR). Eur Heart J 2016;37:2315-81.

40 Xie X, Wu Q, Hao Y, et al. Identifying determinants of socioeconomic inequality in health service utilization among patients with chronic non-communicable diseases in China. PLoS One 2014;9:e100231.

41 de Sousa MF. [The Family Health Program in Brazil: analysis of access to basic care]. Rev Bras Enferm 2008;61:153-8.

42 Santos LMP, Costa AM, Girardi SN. Programa MAIS Médicos: uma ação efetiva para reduzir iniquidades em saúde. Ciênc. saúde coletiva 2015;20:3547-52.

43 Malta DC, Oliveira TP, Santos MAS, et al. Avanços do Plano de Ações Estratégicas para O Enfrentamento das Doenças Crônicas não Transmissíveis no Brasil, 2011-2015. Epidemiol Serv Saúde 2016;25.

44 MINISTÉRIO DA SAÚDE. Brasil. Plano de ações estratégicas para 0 enfrentamento das doenças crônicas $E$ agravos não transmissiveis no Brasil 2021-2030. 122. Brasília DF, 2020.

45 Mackenbach JP, Valverde JR, Artnik B, et al. Trends in health inequalities in 27 European countries. Proc Natl Acad Sci U S A 2018;115:6440-5.

46 Oreiro JL. A grande recessão brasileira: diagnóstico e uma agenda de política econômica. Estudos Avançados 2017;31:75-88.

47 Bernal RTI, Malta DC, de Araújo TS, et al. Inquerito POR telefone: pesos de pos-estratificacao para corrigir vicios de baixa cobertura em Rio Branco, AC. Rev. Saúde Pública 2013;47:316-25. 